\title{
Upregulation of FAM83D affects the proliferation and invasion of hepatocellular carcinoma
}

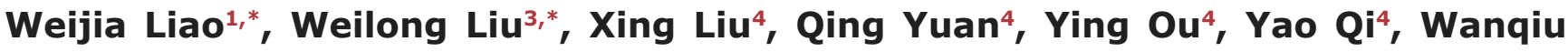 \\ Huang $^{5}$, Yun Wang ${ }^{4}$ and Jian Huang ${ }^{1,2,3,4}$ \\ ${ }^{1}$ Laboratory of Hepatobiliary and Pancreatic Surgery, Affiliated Hospital of Guilin Medical University, Shanghai Center for \\ Systems Biomedicine, Shanghai Jiao Tong University, Shanghai, China \\ ${ }^{2}$ Key Laboratory of Systems Biomedicine (Ministry of Education), Collaborative Innovation Center of Systems Biomedicine, \\ Shanghai Center for Systems Biomedicine, Shanghai Jiao Tong University, Shanghai, China \\ 3 Shenzhen Key Laboratory of Infection and Immunity, Shenzhen Third People's Hospital, Guangdong Medical College, \\ Shenzhen, China \\ ${ }^{4}$ Shanghai-MOST Key Laboratory for Disease and Health Genomics, Chinese National Human Genome Center, Shanghai, \\ China \\ ${ }^{5}$ Tongji Medical College, Huazhong University of Science and Technology, Wuhan, China \\ * These authors have contributed equally to this work
}

Correspondence to: Jian Huang, email: huangjchgc@hotmail.com

Keywords: hepatocellular carcinoma; FAM83D; up-regulation; overall survival; methylation

Received: March 20,2015 Accepted: May 30, $2015 \quad$ Published: June 10, 2015

This is an open-access article distributed under the terms of the Creative Commons Attribution License, which permits unrestricted use, distribution, and reproduction in any medium, provided the original author and source are credited.

\section{ABSTRACT}

The identification of potential oncogenes plays an important role in finding novel therapeutic targets for many cancers, including hepatocellular carcinoma (HCC), which is one of the most common cancers worldwide. In our previous research, using microarray technology, we found that FAM83D was overexpressed in HCCs. However, whether the overexpression of FAM83D contributes to hepatocarcinogenesis remains unclear. In this study, we found that FAM83D was significantly upregulated in $76.6 \%$ (167 of 218) of the HCC specimens at the mRNA level and in $69.44 \%$ ( 50 of 72 ) of the HCC specimens at the protein level compared with adjacent non-cancerous liver specimens, as indicated by RT-PCR and immunohistochemical staining, respectively. The FAM83D mRNA expression level was positively correlated with the level of alphafetoprotein (AFP) ( $\geq 100 \mathrm{ng} / \mathrm{ml}$ ), the clinical TNM stage, the presence of a portal vein tumor thrombus (PVTT), disease-free survival (DFS) and the overall survival (OS) time of the HCC patients $(P<0.05)$. Knocking down FAM83D significantly promoted the growth of Huh7 and HepG2 cells, as demonstrated in an RNA interference assay. Moreover, the DNA methylation status of the FAM83D promoter was significantly reduced in the HCC specimens with overexpression of FAM83D gene. Our data suggest that the upregulation of $F A M 83 D$, a potential oncotarget gene, may be triggered by epigenetic events and can contribute to hepatocarcinogenesis.

\section{INTRODUCTION}

Hepatocellular carcinoma (HCC), the sixth most prevalent type of cancer, is the third leading cause of cancer-related mortality worldwide [1]. The prognosis of HCC remains poor, mainly because the recurrence rates are high even after surgical resection; tumor recurrence complicates more than $70 \%$ of cases at five years after resection $[2,3]$. Although surgical resection is a potentially curative treatment for $\mathrm{HCC}$, and despite the availability of improved diagnostic techniques and advances in surgical and nonsurgical therapies for the disease, the clinical outcome of HCC remains poor [4]. Therefore, the identification of the molecular mechanisms underlying the development and progression of HCC is of particular importance. Such research might lead to a breakthrough in the field of HCC diagnosis, treatment and prevention, and it may enable improved post-surgical outcomes for HCC. 
In this study, we report that that the expression of FAM $83 D$ is increased in HCC tissues, as assessed by an analysis of the whole-genome expression profiles on chips of hepatitis B virus-induced HCC. To further investigate the relationship between FAM $83 D$ and HCC in humans, we evaluated the expression level of FAM $33 D$ in HCC tissues using quantitative real-time PCR (qRT-PCR) and immunohistochemistry (IHC). Additionally, we conducted a comparative analysis with the clinical pathological data. Moreover, we compared and analyzed the expression levels of $F A M 83 D$ in normal liver tissues, fetal liver tissues and HCC cell lines, and we examined its influence on the growth of HCC cell lines by silencing its expression using RNA interference (RNAi). This research provides a foundation for understanding the function of FAM $83 D$ in the development and progression of HCC.

\section{RESULTS}

\section{FAM83D is upregulated at the mRNA level in HCC tissues}

Using a semi-quantitative RT-PCR assay, we found that FAM $83 D$ was significantly upregulated in $90 \%$ $(18 / 20)$ of the HCC specimens compared with the adjacent non-cancerous liver samples (Figure 1A). In addition, using the same technique, we found that FAM $83 D$ was highly expressed in the HCC cell lines SMMC7721, PLC, MHCC97H, QGY7701, QGY7703, Huh7, HepG2, BEL7402, BEL7404 and BEL7405, whereas there was weak expression in MHCC-LM6, MHCC-LM3, MHCC97L and Hep3B cells. There was no expression in the two normal liver cell lines LO2 and WRL68 or in the two HCC cell lines SK-hep1 and YY8103 (Figure 1B). Compared with normal liver tissues, FAM 33 D was more highly expressed in human fetal liver tissues (Figure 1C).
A

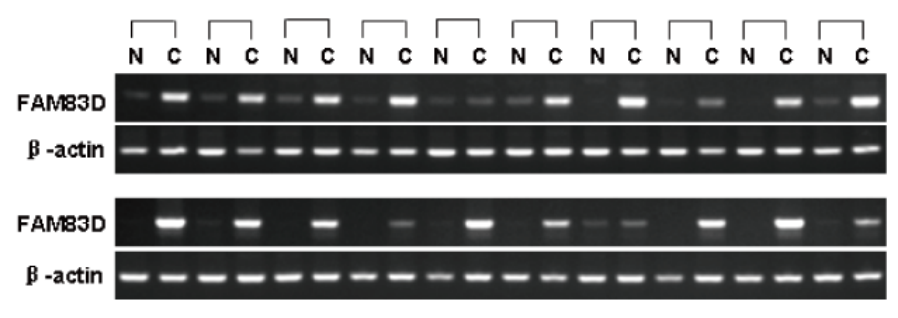

B

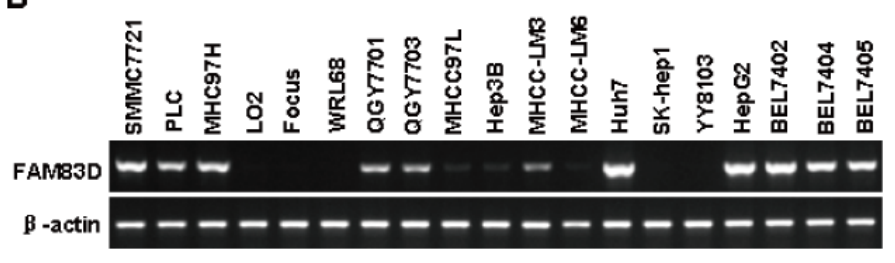

C

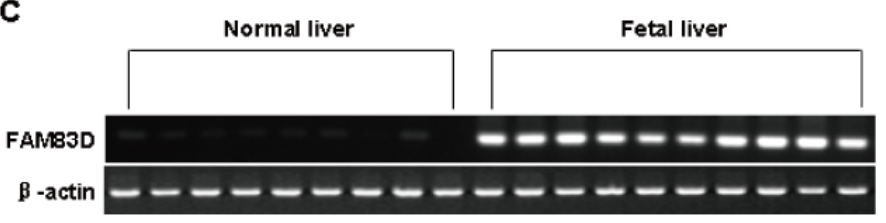

D
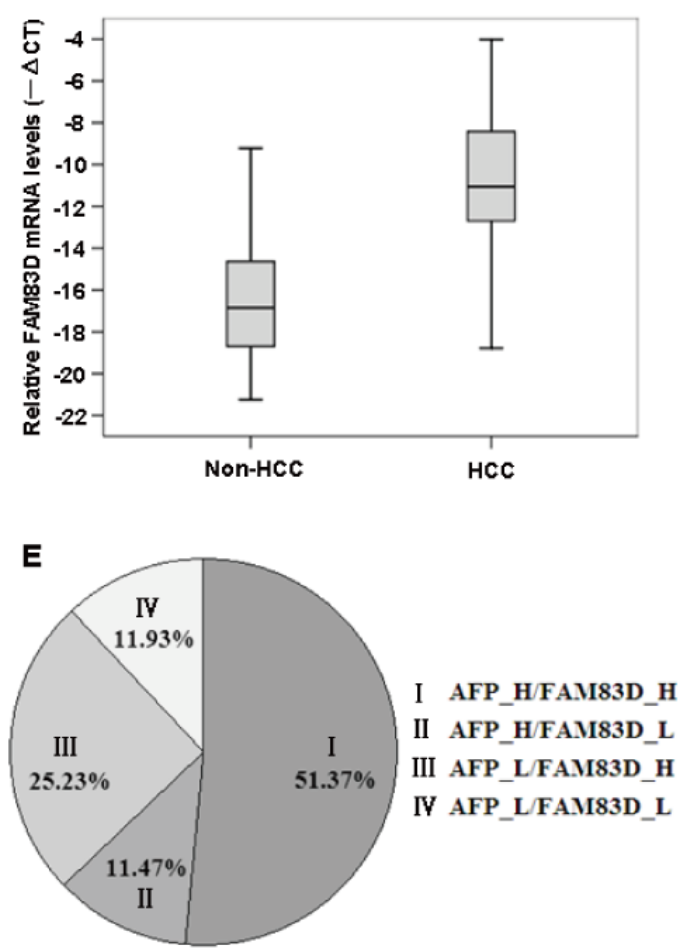

Figure 1: The results of RT-PCR and real-time RT-PCR analyses of the FAM83D mRNA expression in tissue specimens. A.-C. The FAM $83 D$ mRNA level was measured in $20 \mathrm{HCC}$ tissue specimens and in the corresponding adjacent non-cancerous (non-HCC) tissue samples A., 19 human HCC cell lines B., 9 normal liver tissue samples and 10 fetal liver tissue samples C. by RT-PCR. $A C T B$ served as an internal control. The PCR products were visualized by electrophoresis on $2 \%$ agarose gels. D. The mRNA level of FAM83D in 218 paired HCC specimens and the adjacent non-cancerous liver tissue were determined by quantitative real-time PCR. ACTB was used as an internal control. The line within each box represents the median $-\Delta \mathrm{Ct}$ value; the upper and lower edges of each box represent the 75th and 25th percentiles, respectively; the upper and lower bars indicate the highest and lowest values determined, respectively. E. The results of a real-time RT-PCR analysis of the expression status of FAM 83 D and AFP in $218 \mathrm{HCC}$ specimens examined. The numbers represent the percentages of FAM 83 - and/or AFP-positive HCC specimens. 
Table 1: Correlation between the clinicopathologic variables and FAM83D expression in HCC

\begin{tabular}{|c|c|c|c|c|c|c|}
\hline \multirow{2}{*}{ Clinical character } & \multirow{2}{*}{$\begin{array}{l}\text { Clinical } \\
\text { Groups }\end{array}$} & \multirow{2}{*}{$\begin{array}{l}\text { No.of } \\
\text { patients }\end{array}$} & \multicolumn{2}{|c|}{ FAM83D } & \multirow{2}{*}{$x^{2}$} & \multirow{2}{*}{$p$ value } \\
\hline & & & High (\%) & Low $(\%)$ & & \\
\hline \multirow[t]{2}{*}{ Age (years) } & $<55$ & 142 & $107(75.4)$ & $35(24.6)$ & 0.357 & 0.550 \\
\hline & $\geq 55$ & 76 & $60(78.9)$ & $16(21.1)$ & & \\
\hline \multirow[t]{2}{*}{ Gender } & Female & 32 & $22(68.8)$ & $10(31.2)$ & 1.291 & 0.256 \\
\hline & Male & 186 & $145(78.0)$ & $41(22.0)$ & & \\
\hline \multirow[t]{2}{*}{ Family history } & No & 183 & $142(77.6)$ & $41(22.4)$ & 0.624 & 0.430 \\
\hline & Yes & 35 & $25(71.4)$ & $10(28.6)$ & & \\
\hline \multirow[t]{2}{*}{ HBsAg } & Negative & 39 & $31(79.5)$ & $8(20.5)$ & 0.220 & 0.639 \\
\hline & Positive & 179 & $136(76.0)$ & $43(24.0)$ & & \\
\hline \multirow[t]{2}{*}{$\operatorname{AFP}(\mathrm{ng} / \mathrm{ml})$} & $<100$ & 81 & $55(67.9)$ & $26(32.1)$ & 5.449 & 0.020 \\
\hline & $\geq 100$ & 137 & $112(81.8)$ & $25(18.2)$ & & \\
\hline \multirow[t]{2}{*}{ Tumor size $(\mathrm{cm})$} & $<5$ & 52 & $37(71.1)$ & $15(28.9)$ & 1.132 & 0.287 \\
\hline & $\geq 5$ & 166 & $130(78.3)$ & $36(21.7)$ & & \\
\hline \multirow[t]{2}{*}{ Cirrhosis } & No & 20 & $15(75.0)$ & $5(25.0)$ & 0.032 & 0.859 \\
\hline & Yes & 198 & $152(76.8)$ & $46(23.2)$ & & \\
\hline \multirow[t]{2}{*}{ Tumor number } & Single & 146 & $111(76.0)$ & $35(24.0)$ & 0.082 & 0.774 \\
\hline & Multiple & 72 & $56(77.8)$ & $16(22.2)$ & & \\
\hline \multirow[t]{2}{*}{ Wine-drinking } & No & 101 & $79(78.2)$ & $22(21.8)$ & 0.273 & 0.601 \\
\hline & Yes & 117 & $88(75.2)$ & $29(24.8)$ & & \\
\hline \multirow[t]{2}{*}{ TNM stage } & I-II & 105 & $72(68.6)$ & $33(31.4)$ & 7.296 & 0.007 \\
\hline & III-IV & 113 & $95(84.1)$ & $18(15.9)$ & & \\
\hline \multirow[t]{2}{*}{ PVTT } & No & 162 & $118(72.8)$ & $44(27.2)$ & 4.991 & 0.025 \\
\hline & Yes & 56 & $49(87.5)$ & $7(12.5)$ & & \\
\hline \multirow[t]{2}{*}{ Metastasis } & No & 185 & $141(76.2)$ & $44(23.8)$ & 0.103 & 0.749 \\
\hline & Yes & 33 & $26(78.8)$ & $7(21.2)$ & & \\
\hline \multirow[t]{2}{*}{ Recurrence } & No & 140 & $102(72.9)$ & $38(27.1)$ & 3.068 & 0.080 \\
\hline & Yes & 78 & $65(83.3)$ & $13(16.7)$ & & \\
\hline \multirow[t]{2}{*}{ AST (U/1) } & $<40$ & 98 & $75(76.5)$ & $23(23.5)$ & 0.001 & 0.981 \\
\hline & $\geq 40$ & 120 & $92(76.7)$ & $28(23.3)$ & & \\
\hline \multirow[t]{2}{*}{ NLR } & $<2.31$ & 127 & $97(76.4)$ & $30(23.6)$ & 0.009 & 0.925 \\
\hline & $\geq 2.31$ & 91 & $70(76.9)$ & $21(23.1)$ & & \\
\hline
\end{tabular}

* FAM83D High: $2^{-\Delta \Delta C T}>1$; FAM83D Low: $2^{-\Delta \Delta C T} \leq 1$; HBsAg, hepatitis B surface antigen; AFP, alpha-fetoprotein; TNM, tumor-node-metastasis; PVTT, portal vein tumor thrombus; Metastasis, distant metastasis or lymph node metastasis; AST, aspartate aminotransferase; NLR, neutrophil to lymphocyte ratio.

This result implies that the expression level of FAM83D is closely related to the development of the liver. Considering the limitations of the RT-PCR method, the mRNA level of FAM 30 was also evaluated in 218 cases by real time RT-PCR. Of these 218 cases, $76.6 \%$ (167) of the HCCs showed at least a 2-fold increase in the FAM $83 D$ mRNA level (normalized to the $A C T B$ level) in each sample, compared with that of the corresponding non-cancerous livers. These data support the semi-quantitative RT-PCR results indicating that FAM $83 D$ is overexpressed in HCCs 


\section{$(P<0.001$, Figure 1D).}

Interestingly, the expression of FAM $83 D$ and serum AFP did not completely overlap in the 218 HCC specimens examined by real-time RT-PCR. The expression of FAM $83 D$ and the serum AFP level were simultaneously high in $112(51.37 \%)$ of the 218 HCC cases. FAM $83 D$ was not significantly expressed in only $25(11.47 \%)$ of the 218 cases with a high AFP level. Surprisingly, overexpression of FAM 83 D, but not AFP, was evident in $25.23 \%$ (55 of 218) of the HCC specimens (Figure 1E), suggesting that FAM83D may be considered to be a novel candidate biomarker for the pathogenesis of HCC.

Notably, our current findings indicated that the upregulation of $F A M 83 D$ was not significantly correlated with gender, age ( $\geq 50$ or $<50$ years old), tumor size $(\geq 5$ or $<5 \mathrm{~cm}$ ), family history, HBsAg expression, the size and the number of tumors, the presence of liver cirrhosis, alcohol consumption, distant metastasis or lymph node metastasis, postoperative recurrence, the level of AST, or the NLR $(P>0.05$, Table 1). However, the upregulation of FAM $33 D$ positively correlated $(P<0.05)$ with the level of $\operatorname{AFP}(P=0.020)$, the presence of PVTT $(P=0.025)$ and the clinical TNM stage $(P=0.007)$ (Table 1$)$.

Furthermore, we used tissue chips to detect the expression of FAM83D at the protein level in $72 \mathrm{HCC}$ tissues and the adjacent non-cancerous liver tissue specimens. We found that the FAM83D protein was overexpressed in $69.44 \%(50 / 72)$ of the HCCs, but only $12.5 \%$ (9 of 72) of the non-HCC tissues stained positively for FAM83D, and the difference in FAM83D staining between the HCC and non-HCC tissues was statistically significant $(P<0.001)$. The expression of the FAM83D protein was not detected in normal liver tissues (Figure 2).
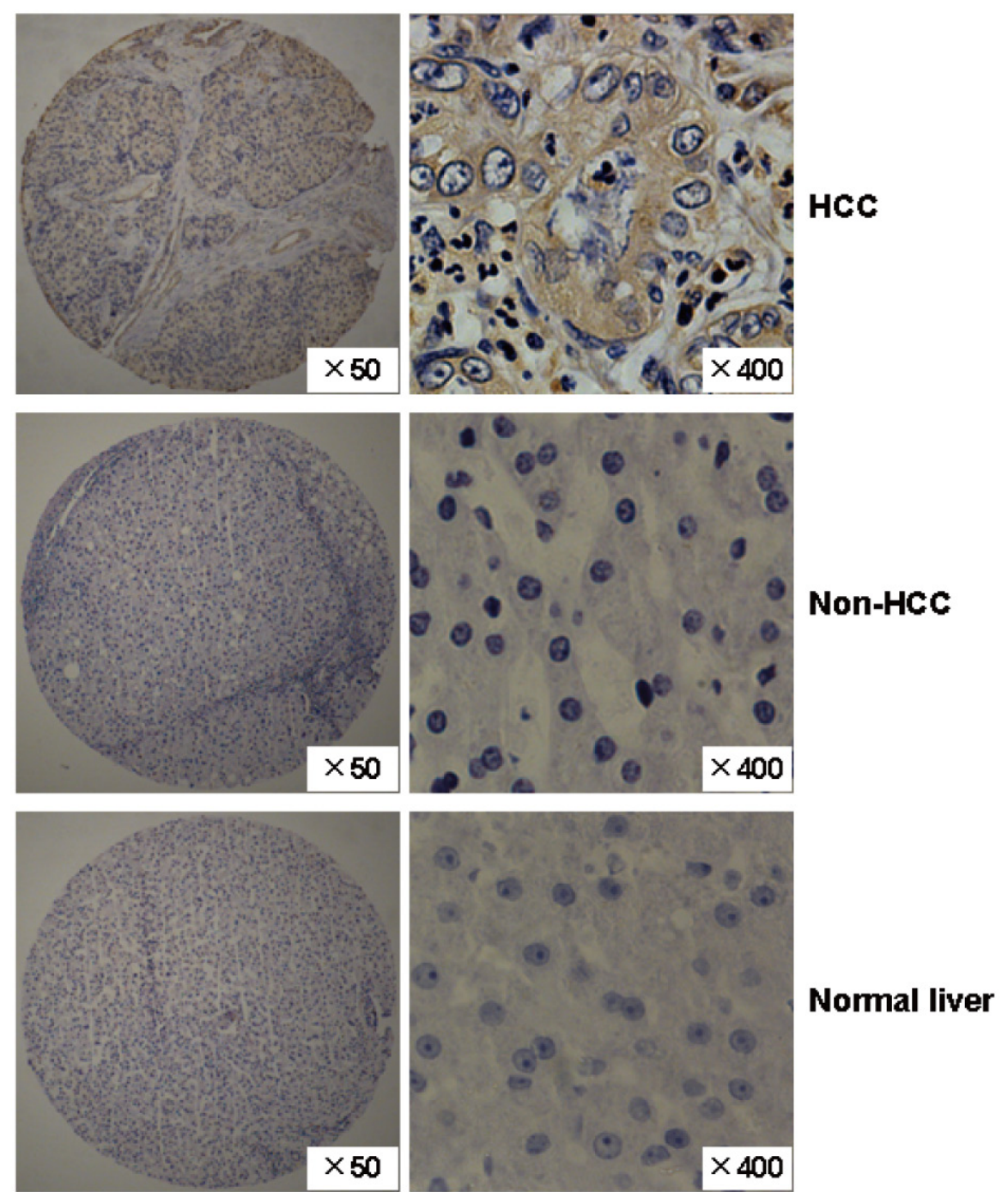

Figure 2: The expression pattern of the FAM83D protein in HCC specimens. Representative immunohistochemical staining of a pair of HCC specimens and their corresponding non-cancerous tissues, and normal liver tissues, as determined using an anti-FAM83D antibody on a tissue array containing 72 pairs of HCC specimens. The nuclei were counterstained with hematoxylin. Original magnification, $\times 50$ (left, tissue chip); $\times 400$ (right; HCC, non-HCC and normal liver). 
Table 2: Association between FAM83D expression level or clinical parameters and disease-free survival/overall survival

\begin{tabular}{|c|c|c|c|c|c|c|c|c|}
\hline \multirow{2}{*}{ Clinical character } & \multirow{2}{*}{ Category } & \multirow{2}{*}{$\begin{array}{l}\text { No.of } \\
\text { patients }\end{array}$} & \multicolumn{3}{|c|}{ Disease-free survival (months) } & \multicolumn{3}{|c|}{ Overall survival (months) } \\
\hline & & & Mean & $95 \% \mathrm{CI}$ & $p$ value & Mean & $95 \% \mathrm{CI}$ & $p$ value \\
\hline \multirow[t]{2}{*}{ FAM83D expression } & Low & 51 & 50.61 & $40.81-60.44$ & 0.002 & 54.98 & $46.09-63.94$ & 0.004 \\
\hline & High & 167 & 32.15 & 27.04-37.12 & & 39.86 & $35.10-44.65$ & \\
\hline \multirow[t]{2}{*}{ Age (years) } & $<55$ & 142 & 36.94 & $31.09-42.83$ & 0.996 & 43.16 & $37.75-48.58$ & 0.952 \\
\hline & $\geq 55$ & 76 & 36.25 & $28.72-43.68$ & & 44.16 & $37.09-51.22$ & \\
\hline \multirow[t]{2}{*}{ Gender } & Female & 32 & 38.81 & $27.66-49.89$ & 0.212 & 52.03 & $40.88-63.19$ & 0.144 \\
\hline & Male & 186 & 35.53 & $30.60-40.53$ & & 41.99 & $37.36-46.64$ & \\
\hline \multirow[t]{2}{*}{ Family history } & No & 183 & 35.69 & $30.65-40.70$ & 0.223 & 42.27 & $37.61-46.94$ & 0.161 \\
\hline & Yes & 35 & 44.42 & $32.32-56.54$ & & 51.02 & $39.90-62.13$ & \\
\hline \multirow[t]{2}{*}{$\mathrm{HBsAg}$} & Negative & 39 & 34.64 & $23.52-45.58$ & 0.868 & 44.46 & $34.72-54.18$ & 0.961 \\
\hline & Positive & 179 & 37.08 & $31.91-42.24$ & & 43.28 & $38.47-48.07$ & \\
\hline \multirow[t]{2}{*}{$\mathrm{AFP}(\mathrm{ng} / \mathrm{ml})$} & $<100$ & 81 & 44.43 & $37.27-51.59$ & 0.002 & 51.86 & $45.59-58.14$ & 0.001 \\
\hline & $\geq 100$ & 137 & 30.60 & $24.71-36.47$ & & 36.82 & $31.22-42.45$ & \\
\hline \multirow[t]{2}{*}{ Median size $(\mathrm{cm})$} & $<5$ & 52 & 63.62 & $55.10-72.08$ & $<0.001$ & 68.88 & $62.23-75.55$ & $<0.001$ \\
\hline & $\geq 5$ & 166 & 28.23 & 23.41-33.09 & & 35.68 & $31.05-40.32$ & \\
\hline \multirow[t]{2}{*}{ Cirrhosis } & No & 20 & 30.79 & $15.61-46.04$ & 0.379 & 38.11 & $24.35-51.86$ & 0.493 \\
\hline & Yes & 198 & 37.38 & $32.44-42.27$ & & 44.23 & $39.69-48.78$ & \\
\hline \multirow[t]{2}{*}{ Tumor number } & Single & 146 & 43.22 & $37.42-49.05$ & $<0.001$ & 49.75 & $44.58-54.95$ & $<0.001$ \\
\hline & Multiple & 72 & 22.81 & $16.35-29.16$ & & 31.04 & $24.22-37.83$ & \\
\hline \multirow[t]{2}{*}{ Wine-drinking } & No & 101 & 41.14 & $33.84-48.49$ & 0.155 & 47.27 & $40.59-5395$ & 0.103 \\
\hline & Yes & 117 & 33.76 & $27.66-39.78$ & & 40.62 & $35.02-46.22$ & \\
\hline \multirow[t]{2}{*}{ TNM stage } & I-II & 105 & 51.52 & $44.81-58.13$ & $<0.001$ & 58.57 & $53.01-64.13$ & $<0.001$ \\
\hline & III-IV & 113 & 22.60 & $17.55-27.81$ & & 29.56 & $24.19-34.94$ & \\
\hline \multirow[t]{2}{*}{ PVTT } & No & 162 & 41.59 & $36.07-47.18$ & $<0.001$ & 48.66 & $43.67-53.68$ & $<0.001$ \\
\hline & Yes & 56 & 22.47 & $15.37-29.42$ & & 28.86 & $21.63-36.10$ & \\
\hline \multirow[t]{2}{*}{ Metastasis } & No & 185 & 40.12 & $34.94-45.20$ & $<0.001$ & 46.51 & $41.80-51.21$ & $<0.001$ \\
\hline & Yes & 33 & 17.33 & $10.13-24.52$ & & 26.78 & $18.14-35.42$ & \\
\hline \multirow[t]{2}{*}{ AST (U/l) } & $<40$ & 98 & 49.24 & $42.08-56.17$ & $<0.001$ & 55.95 & $49.83-62.07$ & $<0.001$ \\
\hline & $\geq 40$ & 120 & 27.03 & $21.26-32.64$ & & 33.65 & $28.26-39.08$ & \\
\hline \multirow[t]{2}{*}{ NLR } & $<2.31$ & 127 & 44.07 & $37.58-50.43$ & 0.001 & 50.24 & $44.52-55.95$ & $<0.001$ \\
\hline & $\geq 2.31$ & 91 & 26.93 & $20.82-33.09$ & & 34.39 & $28.29-40.51$ & \\
\hline \multirow[t]{2}{*}{ Recurrence } & No & 140 & & & & 39.87 & $34.08-45.66$ & 0.073 \\
\hline & Yes & 78 & & & & 48.67 & $42.40-54.94$ & \\
\hline
\end{tabular}

CI, confidence interval; HBsAg, hepatitis B surface antigen; AFP, alpha-fetoprotein; TNM, tumor-node-metastasis; PVTT, portal vein tumor thrombus; Metastasis, distant metastasis or lymph node metastasis; AST, aspartate aminotransferase; NLR, neutrophil to lymphocyte ratio. 


\section{The relationship between $F A M 83 D$ upregulation in HCCs and survival time}

A Kaplan-Meier survival analysis showed that a higher FAM $33 D$ expression level was associated with a shorter disease-free survival (DFS) and overall survival (OS) (Figure 3A and 3B). A univariate analysis revealed that there was an obvious association of the clinical parameters with both the DFS and OS (Table 2). The 5 -year DFS rates of patients with low FAM 33 D expression was $51.8 \%$, compared with $26.4 \%$ for patients with high FAM $83 D$ expression $(P=0.002$; Figure $3 \mathrm{~A})$. The mean DFS in patients with low FAM $83 D$ expression was 50.61 months [95\% confidence interval (CI), 40.81-60.44] compared with 32.15 months (95\% CI, 27.04-37.12) in patients with high FAM $83 D$ expression. The 5-year OS rates of patients with low FAM $83 D$ expression was $57.5 \%$ compared with $32.6 \%$ for patients with high FAM $33 D$ expression ( $P=0.004$; Figure $3 \mathrm{~B})$. The mean OS values in the low and high FAM 83 D expression groups were 54.98 months (46.09-63.94) and 39.86 months (35.10$44.65)$, respectively. In addition to a high FAM $83 D$ expression level, a value of AFP $\geq 100 \mathrm{ng} / \mathrm{ml}$, a tumor $\geq 5$ $\mathrm{cm}$, the presence of multiple tumors, TNM stage III-IV, the presence of PVTT, the presence of distant metastasis or lymph node metastasis, AST $\geq 40 \mathrm{U} / 1$ and NLR $\geq 2.31$ were associated with a shorter DFS and OS (Table 2).

While clarifying the specific subgroups of patients negatively influenced by FAM $83 D$ upregulation, we found that FAM $83 D$ was highly expressed in patients with tumors $\geq 5 \mathrm{~cm}$ and in the non-PVTT cases (Figure $3 \mathrm{G}, 3 \mathrm{H}$ ), and the prognostic significance of FAM $83 D$ was retained in both of these subgroups (Figure 3C-3F). In the subgroup with tumors $\geq 5 \mathrm{~cm}$, high FAM $83 D$ expression showed apparent prognostic value for predicting a poorer DFS $(P$ $=0.006)$ and $\mathrm{OS}(P=0.016)$ (Figure 3C, 3D). In addition, the finding that high FAM $83 D$ expression significantly correlated with a shorter DFS $(P=0.013)$ and OS $(P=$ 0.023 ) was observed in the subgroup of HCC with nonPVTT (Figure 3E, 3F). These findings suggest that the level of FAM 83 D may serve as a prognostic molecular marker for some subgroups of HCC patients.

After adjusting for other confounding factors, the 4 independent factors identified (high FAM $83 D$ expression in HCC tissues, AFP $\geq 100 \mathrm{ng} / \mathrm{ml}$, tumor size $\geq 5 \mathrm{~cm}$ and AST $\geq 40 \mathrm{U} / 1)$ were used in a stepwise multivariate Cox proportional hazard model for both the DFS and OS, and the hazard ratio (HR), $95 \%$ confidence interval (CI), and $P$ values of these four independent predictors are listed in Table 3. The analysis revealed that a value of AFP $\geq 100$ $\mathrm{ng} / \mathrm{ml}$ (HR, $1.515 ; 95 \% \mathrm{CI}, 1.063-2.160, P=0.021)$, tumor size $\geq 5 \mathrm{~cm}$ (HR, 2.768; 95\% CI, 1.550-4.943, $P=0.001)$, AST $\geq 40 \mathrm{U} / 1$ (HR, $1.780 ; 95 \% \mathrm{CI}, 1.226-2.584, P=$ 0.002 ), and high FAM $83 D$ expression (HR, $1.568 ; 95 \%$ CI, 1.112-2.209, $P=0.010$ ) were all independent predictors for the DFS (Table 3). A value of AFP $\geq 100 \mathrm{ng} / \mathrm{ml}$ (HR,
1.770; 95\% CI, 1.128-2.775, $P=0.013$ ), tumor size $\geq 5$ cm (HR, 2.622; 95\% CI, 1.470-4.678, $P=0.001$ ), AST $\geq 40 \mathrm{U} / 1$ (HR, 1.898; 95\% CI, 1.304-2.762, $P=0.001$ ), and high FAM83D expression (HR, 1.629; 95\% CI, 1.138 2.333, $P=0.008)$ were also all independent predictors of the OS (Table 3).

\section{Kaplan-meier analysis of DFS in 218 patients with HCC based on statistically significant clinical parameters}

We established a preoperative prognostic score model by calculating the number of independent predictors (FAM83D, AFP, tumor size, and AST) for each patient. Each factor was allotted a score of 1, and then patients were divided into five categories by their risk scores (RSs) $(0,1,2,3$, and 4). For example, "RS $=0$ " means patients without any of the above factors; this group occupied $2.29 \%$ (5 of 218). "RS $=4$ " means patients with all four factors; it occupied $22.47 \%$ (49 of 218) of patients carrying all four factors (Figure 4). Because no significant differences were found in the DFS between patients with a risk score $=1$ and a risk score $=0$ or 2 (Figure 4A, $P$ $=0.678, P=0.054$, respectively), the groups with a risk score $=0$ or 1 were merged to form a score $\leq 1$ group. When using the combination of the four independent predictors, patients with different RSs showed a significant difference in the DFS (RS $\leq 1 v s . \mathrm{RS}=2, P=0.020$; RS $=2$ vs. $\mathrm{RS}=3, \mathrm{P}=0.000 ; \mathrm{RS}=3 v \mathrm{~s} . \mathrm{RS}=4, P=0.002)$ (Figure 4B). Surprisingly, the proportion of $\mathrm{HCC}$ patients with RS $=4$ was very high, occupying $22.47 \%$ (49 of 218) of total patients, all these patients showed much shorter DFS.

\section{FAM83D promotes cell proliferation, migration and invasion, as determined using RNA interference}

To further examine the functional role of FAM $33 D$ in HCC cells, Huh7 and HepG2 cells were transfected with siRNA duplexes against FAM83D. Three parallel samples were taken from both the siRNA-NC and siRNA-1 groups. We observed 2 fields $(\times 100)$ in each sample, for a total of six sections. When the expression of FAM $83 D$ was silenced in the wound-healing migration assay (the scratch test), microscopic examinations at 0 and $36 \mathrm{~h}$ revealed that the migration of the Huh7 and HepG2 cells was inhibited by FAM $83 D$ silencing (Figure 6A and 6B).

When we inoculated the cells in the upper chambers of a Transwell and counted the Huh7 cells that had penetrated the membrane after 24 hours, $52.00 \pm 4.85$ and $38.20 \pm 4.04$ of the cells had penetrated in the siRNA-NC and siRNA-1 groups. The decrease in the number of cells that had penetrated the membrane in the siRNA-1 group compared with the siRNA-NC group was statistically 

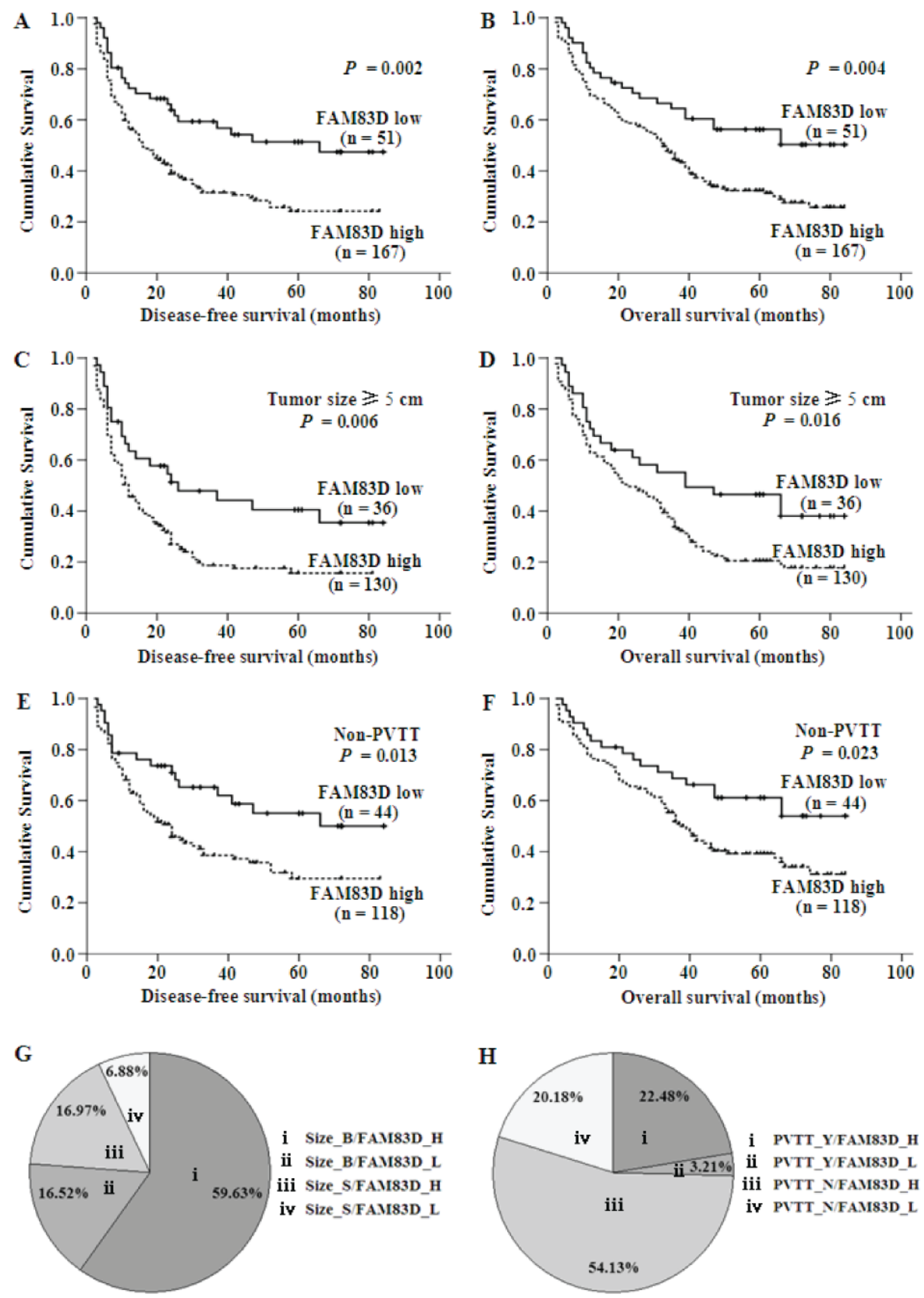

Figure 3: A.-F. The results of the Kaplan-Meier survival analysis showing that patients with high expression of $F A M 83 D$ had a shorter DFS and OS. The green line represents the low expression of FAM $33 D$, whereas the blue line represents the high expression of FAM83D. G. and $\mathbf{H}$. The expression of FAM $83 D$ and a large tumor size or the presence of PVTT did not completely overlap in the 218 HCC specimens. FAM $83 D$ was overexpressed in 130 of the 218 HCC specimens $(59.63 \%)$ with a tumor size $\geq 5 \mathrm{~cm}$ (Size_B), whereas FAM83D was not expressed in only $15(6.88 \%)$ of the cases with a tumor size $<5 \mathrm{~cm}$ (Size_S) (G). FAM83D was overexpressed in 118 of the $218 \mathrm{HCC}$ specimens (54.13\%) without PVTT (PVTT_N), moreover, FAM83D was not expressed in only 7 (3.21\%) cases that had PVTT (PVTT_Y) $(\mathrm{H})$. 

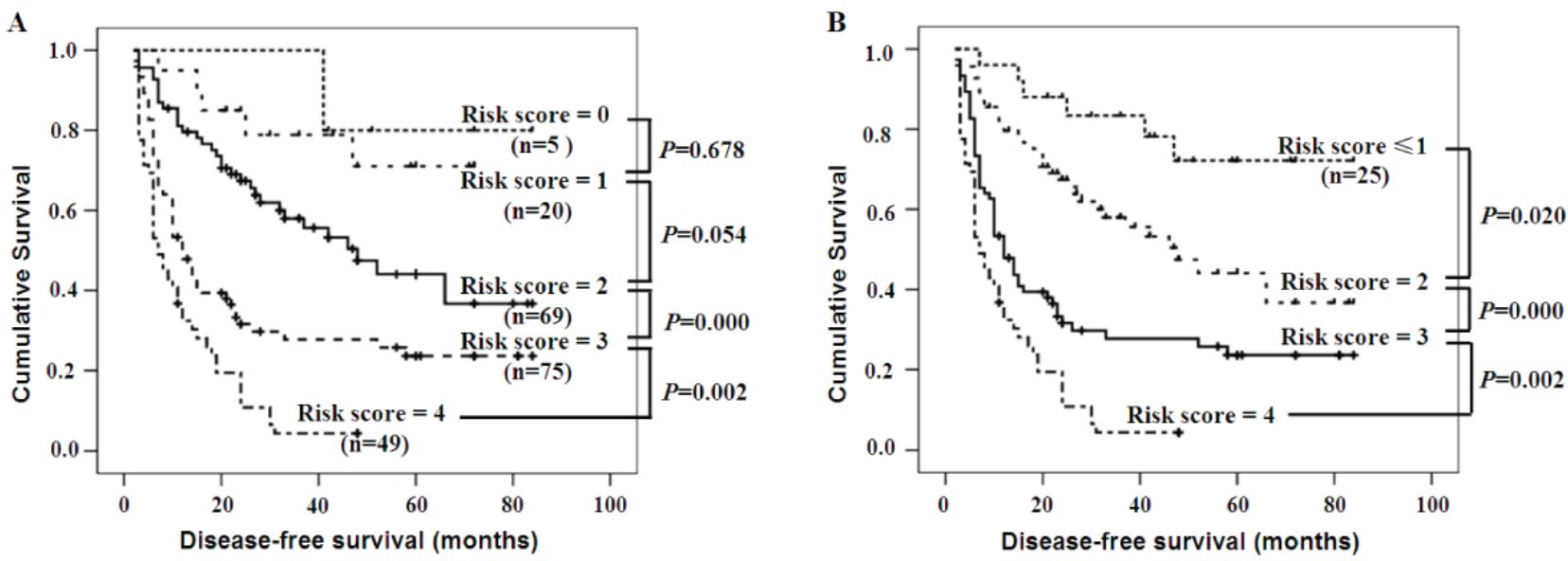

Figure 4: The DFS for patients with various risk scores according to the independent predictors. A. The Kaplan-Meier curves for the five groups of patients showed that there were no significant differences in the disease-free survival rates of patients with scores of 0 to 2 (all $P>0.05$ ), However, there were significant differences in the DFS of patients with scores from 2 to 4 (all $P<0.01$ ). B. There were also significant differences in the DFS after patients with a risk score $=0$ or 1 were merged (all $P<0.01)$.

A

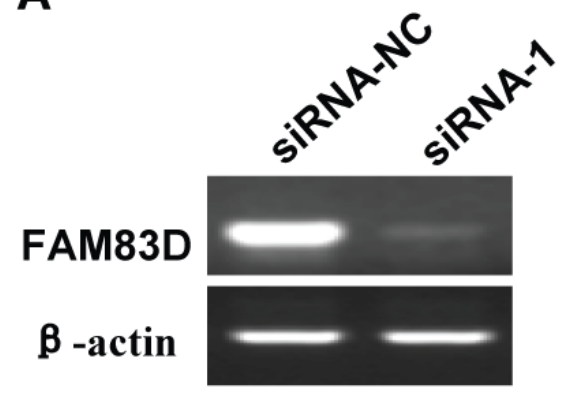

C

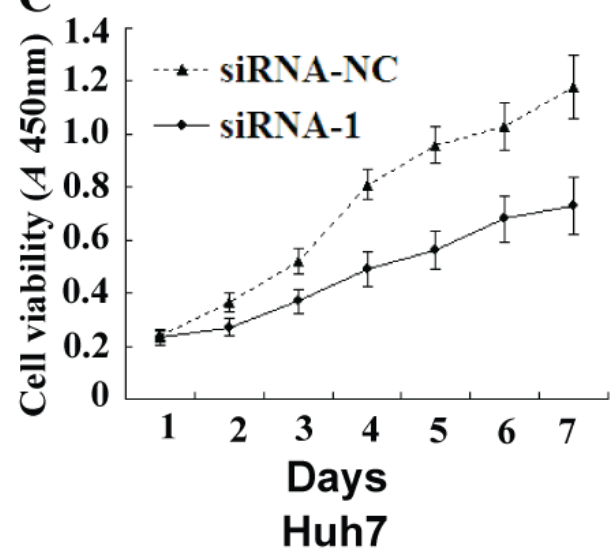

B

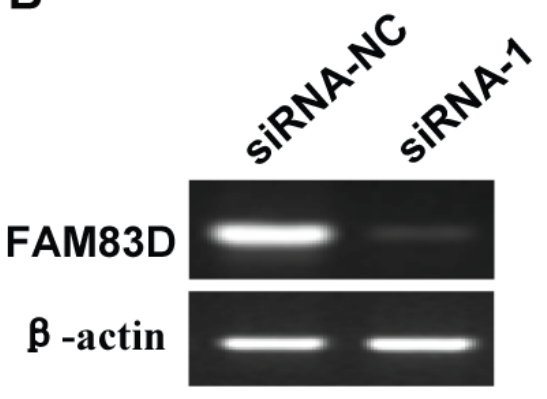

D

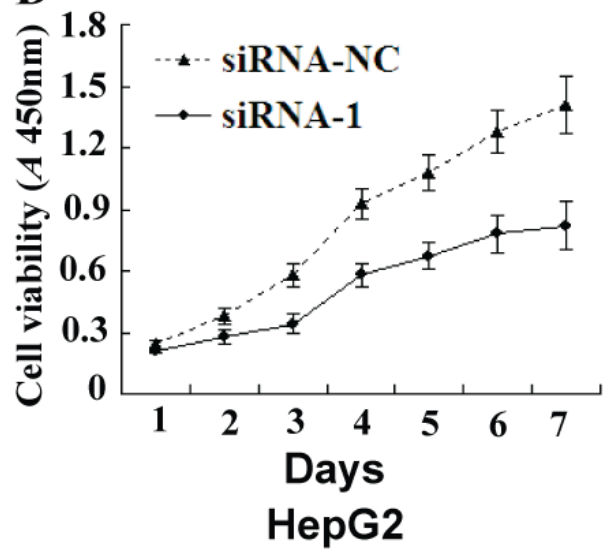

Figure 5: The effects of FAM83D silencing on the growth of HCC cells. A. and B. FAM83D expression was knocked down in Huh7 A. and HepG2 B. cells following transient transfection with siRNA-1, which was confirmed by RT-PCR assay. siRNA-NC (as a control) was transiently transfected into Huh7 and HepG2 cells. C. and D. The growth curves of the Huh7 C. and HepG2 D. cells with FAM83D silencing by siRNA-1 were determined by the CCK-8 assay, and the cells transfected with siRNA-NC served as controls. The experiments were repeated at least three times, and the spots represent the average values of triplicate wells, with standard deviations (SDs) included for each mean value. 
Table 3: Cox multivariate proportional hazard model of independent predictors on disease-free and overall survival

\begin{tabular}{lllll}
\hline \multirow{2}{*}{ Variable } & Disease-free survival & & Overall survival \\
\cline { 2 - 5 } & Hazard ratio $(95 \%$ CI $)$ & $p$ value & Hazard ratio (95\% CI) & $p$ value \\
\hline AFP ng/ml $(\geq 100 v s<100)$ & $1.515(1.063-2.160)$ & 0.021 & $1.770(1.128-2.775)$ & 0.013 \\
Tumor size, cm $(\geq 5 v s<5)$ & $2.768(1.550-4.943)$ & 0.001 & $2.622(1.470-4.678)$ & 0.001 \\
Tumor number $($ multiple $v s$ single) & $1.373(0.953-1.977)$ & 0.089 & $1.366(0.949-1.966)$ & 0.093 \\
TNM stage $($ III-IV $v s$ I-II) & $1.468(0.931-2.316)$ & 0.098 & $1.515(0.957-2.398)$ & 0.076 \\
PVTT (yes $v s$ no) & $1.039(0.682-1.583)$ & 0.860 & $1.046(0.687-1.594)$ & 0.833 \\
Metastasis $($ yes $v s$ no) & $1.453(0.924-2.285)$ & 0.106 & $1.411(0.893-2.228)$ & 0.140 \\
AST $(\mathrm{U} / 1)(\geq 40 v s<40)$ & $1.780(1.226-2.584)$ & 0.002 & $1.898(1.304-2.762)$ & 0.001 \\
NLR $(\geq 2.31 v s<2.31)$ & $1.326(0.938-1.875)$ & 0.110 & $1.301(0.920-1.842)$ & 0.137 \\
FAM83D expression $($ high $v s$ low) & $1.568(1.112-2.209)$ & 0.010 & $1.629(1.138-2.333)$ & 0.008 \\
\hline
\end{tabular}

CI, confidence interval; AFP, alpha-fetoprotein; TNM, tumor-node-metastasis; PVTT, portal vein tumor thrombus; Metastasis, distant metastasis or lymph node metastasis; AST, aspartate aminotransferase; NLR, neutrophil to lymphocyte ratio.
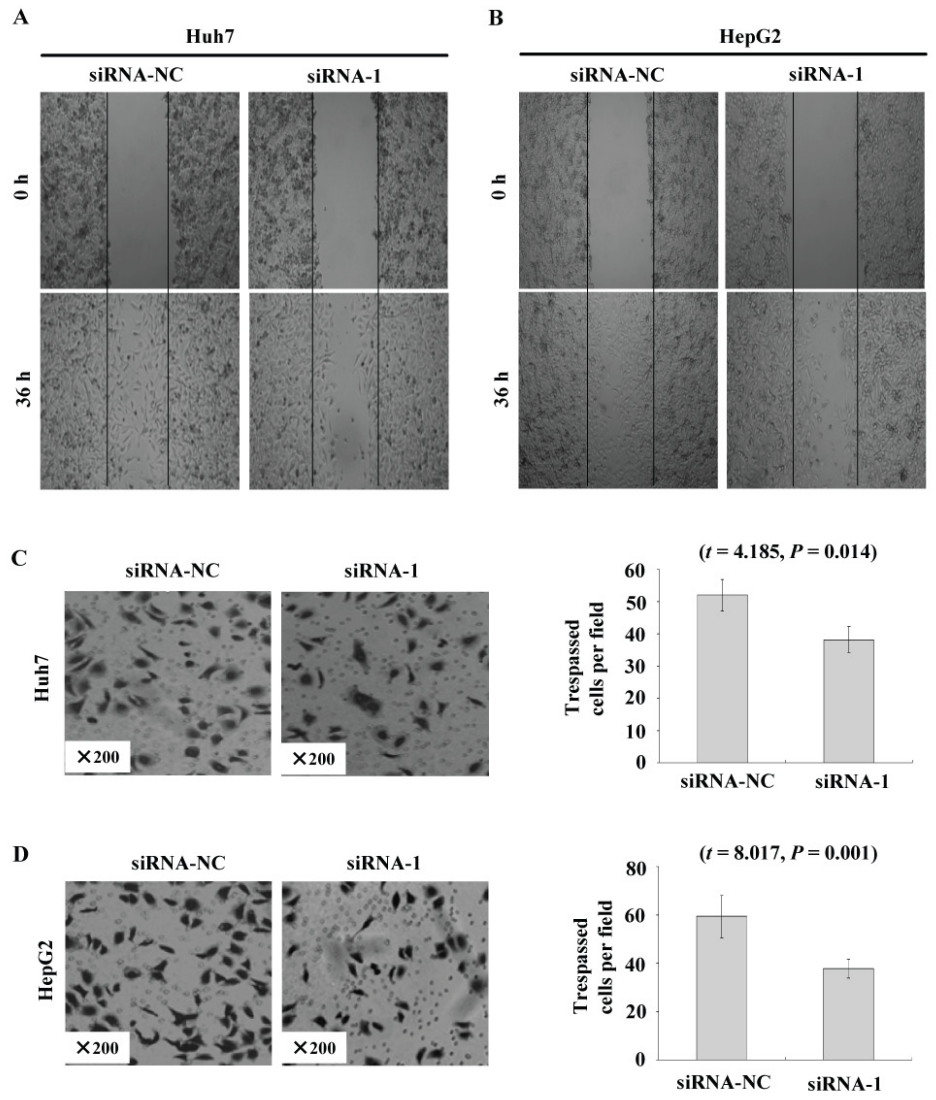

Figure 6: FAM83D modulates HCC cell migration and invasion. A. and B. The migration of Huh7 A. and HepG2 B. cells transfected with siRNA-1 in the wound healing experiments, where siRNA-NC-transfected cells served as a control. C. and D. The invasion of Huh7 C. and HepG2 D. cells transfected with siRNA-1 to knock down FAM83D expression was evaluated with a Matrigel assay, with siRNA-NC serving as a control. The number of migrated cells is represented by the mean values per field (from at least 5 fields) from 3 independent experiments (right) (mean $\pm \mathrm{SD}$ ). 
significant (Figure 6C; $P=0.014$ ). The numbers of penetrating HepG2 cells in the siRNA-NC and siRNA-1 groups were $59.40 \pm 8.71$ and $37.80 \pm 3.96$, respectively. This result demonstrated that there was a significant decrease in cell migration after siRNA-mediated silencing of FAM 33 compared with the siRNA-NC cells (Figure $6 \mathrm{D} ; P=0.001)$. After $F A M 83 D$ had been silenced, invasion by both the Huh7 and HepG2 cells was inhibited.

\section{The DNA methylation status of the FAM83D promoter is reduced in $\mathrm{HCC}$ tissues}

To address whether epigenetic alterations contribute to the dysregulation of FAM $83 D$ in HCCs, we conducted bisulfite DNA sequencing to characterize the methylation status of the FAM $83 D$ promoter in four pairs of HCC and non-HCC specimens. The HCC specimens showed FAM83D overexpression compared with the expression in the non-cancerous tissues. The sequencing data revealed that the FAM $83 D$ promoter methylation was significantly reduced in the majority of $\mathrm{HCC}$ specimens compared with the paired non-cancerous liver tissues (Figure 7). These findings suggest that the upregulation of FAM $83 D$ in HCC may be correlated with the methylation levels of the FAM83D promoter.

\section{DISCUSSION}

FAM 83 , the family with sequence similarity 83, member D (also known as C20orf129, CHICA) is located on chromosome 20 in humans [7]. FAM83D is involved in mitotic processes to regulate cell division [8]. It may be important for mitotic progression and the equal segregation of chromosomes [9]. FAM $83 D$ was previously identified as a putative spindle component in a mass-spectrometry-based spindle inventory [10]. It was initially characterized as a novel spindle protein, termed "CHICA", that was originally identified in a proteomic survey of the human spindle apparatus [10]. Santamaria et al. [8] showed that CHICA coimmunoprecipitates with $\mathrm{Kid}$ and is required for the spindle localization of Kid without affecting its chromosome association. Moreover, upon the depletion of either CHICA or Kid (or both proteins simultaneously), the chromosomes collapsed to the poles of monastrol-induced monopolar spindles.

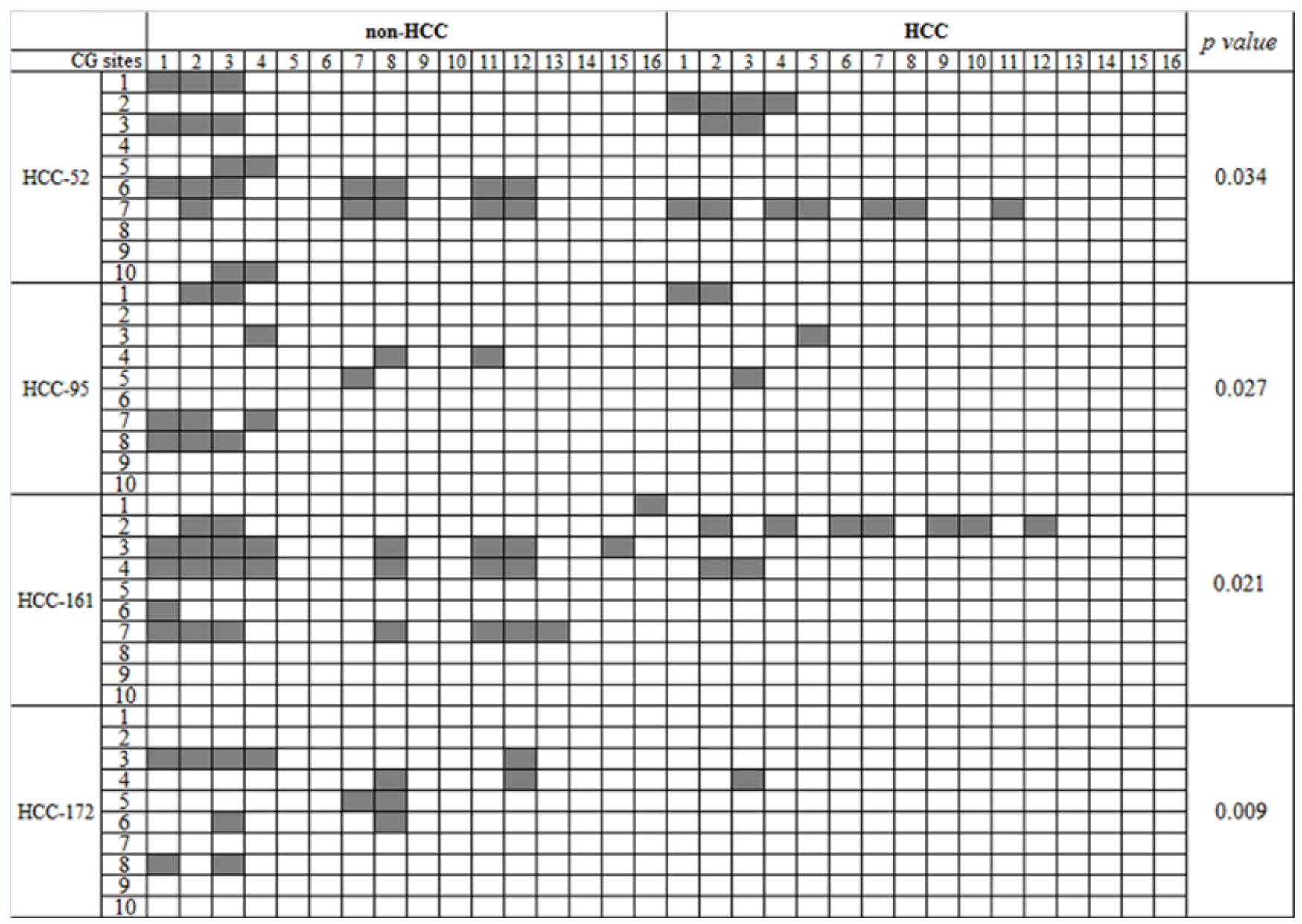

Figure 7: The DNA methylation status of the FAM83D promoter in HCC. The results from the bisulfite sequencing analysis of FAM 83 D promoter $\mathrm{CpG}$ methylation in four pairs of $\mathrm{HCC}$ and non-HCC specimens. Each box indicates a CpG dinucleotide within the $\mathrm{CpG}$ island in the promoter. Gray box indicates methylation cytosine while while box indicates unmethylation cytosine. 
The expression of FAM83D appears to be correlated with miR-210 [11]. Recent reports showed that FAM83D is involved in breast cancer $[12,13]$. However, to our knowledge, there is no information regarding its role in the initiation and/or progression of HCC or the potential clinical implications of FAM $83 D$ expression in $\mathrm{HCC}$ patients. In this study, we confirmed that FAM $83 D$ was highly expressed in HCC tissues compared with the adjacent liver tissues, and through a statistical analysis, we also found that the FAM $83 D$ expression level and the level of AFP ( $\geq 100 \mathrm{ng} / \mathrm{ml}$ ), clinical TNM stage and presence of PVTT showed a positive correlation $(P<0.05)$. The AFP levels have been widely used for the diagnosis and surveillance of HCC. However, the sensitivity and specificity of the AFP levels for HCC surveillance have some limitations because the levels may be normal in up to $40 \%$ of patients with $\mathrm{HCC}$, particularly during the early stages of the disease. Therefore, the identification of other factors affecting the survival of HCC patients, including conventional clinicopathological variables and novel molecular markers, has been a major focus of research in the field. The present study suggests that FAM83D has potential as a novel biomarker for the pathogenesis of HCC, and simultaneously detecting AFP and FAM83D could improve the prognostic accuracy. The expression level of FAM $83 D$ was high in both fetal liver tissues and human HCC cell lines, but there was very low or no expression in the normal liver tissues. Therefore, it may be speculated that FAM $83 D$ plays an important role in maintaining the malignant phenotype of HCC cells, and it might be a gene that is closely related to HCC.

The data obtained from the univariate analysis revealed that high FAM83D expression, AFP $\geq 100 \mathrm{ng} / \mathrm{ml}$, a median size tumor $\geq 5 \mathrm{~cm}$, multiple tumors, TMN stage III-IV, PVTT, distant metastasis or lymph node metastasis, $\mathrm{AST} \geq 40 \mathrm{U} / 1$ and NLR $\geq 2.31$ were all associated with a shorter DFS and OS. In previous studies, the tumor number was shown to be an important determinant of the prognosis of HCC in patients undergoing several types of treatments [14]. Individuals with a single HCC lesion had a relatively higher survival rate than those with multinodular tumors. Compared with multiple nodular HCC, a single tumor is strongly suggested to have better prognosis [14]. The main cause of metastatic and recurrent HCC is the invasion of the portal veins by HCC cells, leading to PVTT. PVTT, a unique disseminating form of intrahepatic HCC metastasis, was previously found to be associated with a poor prognosis $[15,16]$. It is interesting that the NLR had previously been investigated for it prognostic role in HCC [17-20]. In the present study, we found that an NLR $>2.31$ was associated with a worse survival for HCC patients, and those with an elevated NLR $(>2.3)$ had a significantly shorter DFS and OS than those with a low $\operatorname{NLR}(\leq 2.31)$.

After adjusting for other confounding factors, high expression of FAM83D, AFP $\geq 100 \mathrm{ng} / \mathrm{ml}$, median tumor size $\geq 5 \mathrm{~cm}$ and AST $\geq 40 \mathrm{U} / 1$ were also identified as independent prognostic factors for the DFS and OS by the multivariate analysis in this study. In addition, several studies have previously shown that the level of AFP [21, 22], tumor size [23, 24] and AST [25-27] level were related to the DFS and/or OS in patients with HCC. In addition, a tumor size $>5 \mathrm{~cm}$ was a significant risk factor for recurrence after liver resection [23, 24], whereas the tumor size and number may indicate whether the HCC is uni- or multi-focal in origin. Relatively small tumors, particularly those $<5 \mathrm{~cm}$, are associated with a better prognosis $[28,29]$, whereas tumors $>5 \mathrm{~cm}$ are associated with a greater likelihood of vascular invasion and a higher recurrence risk [23, 24, 30]. We used a combination of these 4 independent predictors and separated the HCC patients into four distinct risk score groups with significantly different prognoses. This provided a new risk score for HCC. However, the small sample size of the present study limits its clinical value. It will be necessary to validate the prognostic significance of high FAM83D expression in a larger cohort of HCC patients. Finally, personalized therapy and follow-up for patients with early stage $\mathrm{HCC}$ can be pursued in the near future based on either the FAM $83 D$ level alone, or more likely, on the combination of prognostic factors.

The high invasiveness, anti-apoptotic signaling and high invasive potential of the malignant tumor are key factors involved in the development and progression of HCC $[31,32]$. Therefore, inhibiting a tumor's proliferation and invasion, while also increasing its level of apoptosis, have been major areas of focus in our research. RNA interference is an effective way to decrease a gene's expression, and it might represent an ideal strategy for cancer therapy [33]. siRNA can inhibit a target gene with specificity and high effectiveness, and siRNAs with high rates of inhibition of the target of interest can be easily detected by screening methods. Our in vitro experiments demonstrated that silencing FAM83D inhibited the proliferation, migration, and invasiveness of Huh7 and HepG2 cells. These data suggested that FAM83D has an essential role in mediating the development and progression of HCC.

In summary, we have demonstrated that FAM83D may serve as a powerful prognostic marker and therapeutic target for HCC. FAM 83 D is overexpressed in fetal liver and $\mathrm{HCC}$ tissues, and it contributes to the intrahepatic metastasis of HCC (PVTT) and also represents a new independent prognostic factor for HCC. However, the underlying mechanisms by which FAM $83 D$ exerts its effects require further clarification. Future research should focus on understanding its molecular mechanism(s) of action. 


\section{MATERIALS AND METHODS}

\section{Sources of specimens and cell lines}

The 218 HCC tissue specimens used in this research and the adjacent non-HCC tissues were obtained by surgical excision from the livers of HCC patients at the Affiliated Hospitals of Guilin Medical University between November 2001 and April 2007. The diagnosis of HCC was confirmed by clinical and serological features, ultrasonography (US), computed tomography (CT), magnetic resonance imaging (MRI) and pathological examination, and the diagnoses were consistent with the "Primary Liver Cancer Clinical Diagnosis and Staging Criteria".

The clinicopathological characteristics of these patients, including their age, gender, family history, hepatitis B surface antigen (HBsAg) expression, alphafetoprotein (AFP) level, the size and the number of tumors, concomitant liver cirrhosis, history of alcohol consumption, clinical TNM stage, presence of portal vein tumor thrombus (PVTT), development of distant metastasis or lymph node metastasis, postoperative recurrence, aspartate aminotransferase (AST) level and neutrophil-to-lymphocyte ratio (NLR) were collected, and the results are presented in Table 1. In addition, 9 normal tissue samples were taken from the surrounding tissues of patients with hepatic hemangioma, and the identity of the tissue samples was verified pathologically after the operations. The 10 fetal tissue samples were obtained from aborted fetuses in the obstetrics department of the hospital. All samples were frozen in liquid nitrogen and stored at $-80^{\circ} \mathrm{C}$ immediately after the surgical excision, and the study was approved by the Hospital Ethics Committee affiliated of Guilin Medical University. All subjects provided written informed consent based on the Declaration of Helsinki.

Normal liver cell lines (including LO2 and WRL68) and HCC cell lines (including SMMC7721, PLC, MHCC97H, Focus, QGY7701, QGY7703, MHCC97L, Hep3B, MHCC-LM3, MHCC-LM6, Huh7, SK-hep1, YY8103, HepG2, BEL7402, BEL7404 and BEL7405) were cultured in our laboratory.

We investigated HCC patients with long-term follow-up after surgery. The follow-up studies included serum AFP and US every 2 months and chest radiography every 6 months during the first two postoperative years and at 3-6-month intervals thereafter. CT or MRI was performed if recurrence was suspected due to an abnormal AFP test or US examination. The mean postoperative follow-up term was 35.5 months (median, 21.0 months; range, 2.0 to 84.0 months). The disease-free survival (DFS) was measured from the date of surgery to the date of recurrence, metastasis, death or the last follow-up.
The overall survival (OS) was measured from the date of surgery to the date of death or the last follow-up.

\section{RNA extraction and cDNA synthesis}

Total RNA was isolated from HCC cell lines or frozen tissue samples that were pulverized under liquid nitrogen and extracted using the TRIzol (Invitrogen, Carlsbad, CA, USA) reagent. To reduce the risk of genomic DNA contamination, DNase treatment was performed on 1 to $2 \mu \mathrm{g}$ of RNA by adding $2 \mathrm{U}$ of DNase I (Invitrogen), $1 \mu \mathrm{l}$ DNase buffer, and $0.4 \mu \mathrm{l}$ RNase Out for $15 \mathrm{~min}$ at room temperature. The concentration of RNA was determined by spectrophotometry, and the total RNA integrity was monitored by visualization of ribosomal RNAs (28S and 18S) on 1.2\% agarose gels. First-strand cDNA was synthesized using a PrimeScript RT Reagent Kit (TaKaRa) according to the manufacturer's instructions.

\section{Determination of gene expression by reverse transcription-PCR and quantitative real-time PCR}

Based on the GenBank cDNA sequences, we designed primer sequences for FAM83D (NM_030919.2) and $A C T B$ (encoding $\beta$-actin) using the Primer Premier 5.0 program. In a PubMed BLAST comparative analysis, the designed primer sequences showed comparatively good specificity (the primers were synthesized by Shanghai Biological Engineering Co., Ltd). For the reverse transcription-polymerase chain reaction (RT-PCR), the upstream primer sequence for FAM83D was 5'- AACCACTGACTTC CACAATCCT-3', and the downstream primer sequence was 5'-CAAAACAAACCC CTGTATCCAT-3', which resulted in an amplified fragment of $496 \mathrm{bp}$. $A C T B$ was used an internal control with an upstream primer sequence of 5'-TCAC2CCACACTGTGCCC ATCTACGA-3' and a downstream primer sequence of 5'-CAGCGGAACCGCTCA TTGCCAATGG-3' to amplify a 295-bp fragment. The PCR reaction was

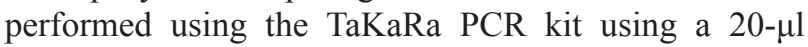
reaction volume. The reaction conditions were $94^{\circ} \mathrm{C}$ for 5 min, followed by 35 cycles (for FAM83D) or 25 cycles (for $A C T B$ ) of $94^{\circ} \mathrm{C}$ for $30 \mathrm{~s}, 55^{\circ} \mathrm{C}$ for $30 \mathrm{~s}, 72^{\circ} \mathrm{C}$ for $30 \mathrm{~s}$; then $5 \mathrm{~min}$ at $70^{\circ} \mathrm{C}$, followed by storage at $4^{\circ} \mathrm{C}$. The PCR products were run on $2 \%$ agarose gels and visualized after staining with ethidium bromide.

The qRT-PCR was performed according to the instructions for the SYBR Premix Ex Taq. We designed the primer sequences to amplify FAM $83 D$ as follows: 5'-ATGGACGGATGGCAAATTAAAC-3' (sense) and 5'-CTGCTCTGGAAGT GAGACAGGA-3' (antisense), with the length of the amplified fragment being $141 \mathrm{bp}$. The primer sequences for the internal control $(A C T B)$ were 
5'-GACAGGATGCAGAAGGAGATTACT-3' (sense) and 5'-TGATCCACATCTGCT GGAAGGT-3' (antisense) (with the length of the amplified fragments being $142 \mathrm{bp}$ ).

The qRT-PCR amplification and data analysis were performed using the ABI Prism 7500 Sequence Detector System from Applied Biosystems (Foster City, CA, USA). Each cDNA sample was mixed with $15 \mu$ l of master mix (SYBR ${ }^{\circledR}$ Green PCR Master Mix, Applied Biosystems). For PCR, an identical amplification protocol was used, and consisted of an initial denaturation step at $95^{\circ} \mathrm{C}$ for $10 \mathrm{~min}$, followed by 40 cycles (denaturation at $95^{\circ} \mathrm{C}$ for $2 \mathrm{sec}$, annealing at $55^{\circ} \mathrm{C}$ for $5 \mathrm{sec}$, extension at $72^{\circ} \mathrm{C}$ for $15 \mathrm{sec}$ ) and fluorescence acquisition at $72^{\circ} \mathrm{C}$. The relative FAM83D mRNA expression was calculated as described in our previous report [5].

\section{Immunohistochemistry (IHC) assay}

Tissue microarrays were prepared according to the following method. Formalin-fixed, paraffin-embedded tissue blocks and the corresponding hematoxylin-eosin (H\&E)-stained slides were overlaid for tissue microarray sampling. The HCC and non-HCC tissue array slides with normal tissue controls (12 cases/24 cores) were reviewed by two histopathologists, and representative tumor areas free from necrotic and hemorrhagic materials were premarked in the paraffin blocks.

The tissue microarray slides were deparaffinized in xylene, rehydrated through a graded series of ethanol, subjected to antigen retrieval by pressure cooking for 3 minutes in ethylenediamine tetraacetic acid (EDTA) buffer $(\mathrm{pH}=8.0)$. Then, the slides were washed in phosphate-buffered saline (PBS) and immersed in 3\% hydrogen peroxide for 20 minutes to block the endogenous peroxidase activity. The slides were preincubated with $10 \%$ normal goat serum at room temperature for 30 minutes to reduce nonspecific binding. Subsequently, the slides were incubated with rabbit polyclonal antiFAM83D (lot": SA110329BV, ABGENT Company, 1:200 dilution) antibodies overnight in a moist chamber at $4{ }^{\circ} \mathrm{C}$, washed in PBS, and incubated with a biotinylated goat anti-rabbit antibody for 1 hour at room temperature. The samples were then stained with 3, 3- diaminobenzidine tetrahydrochloride (DAB). Finally, the sections were counterstained with Mayer's hematoxylin, dehydrated, and mounted. A negative control was obtained by replacing the primary antibody with normal rabbit or mouse IgG. Semiquantitative IHC detection was performed to determine the FAM83D protein levels, and the stained tissue sections were assessed using a 4-point scale as follows: positive cell counts, grades $0-3(0$, no positive cells; $1,<25 \%$ positive cells; $2,25 \%-50 \%$ positive cells; $3,>50 \%$ positive cells). The slides were separately reviewed under light microscopy by two pathologists.

\section{The design and synthesis of RNAi fragments}

Three siRNAs against FAM83D were designed using the Whitehead Institute Web Server (http://jura. wi.mit.edu/bioc/siRNAext/) and were chemically synthesized (Shanghai GenePharma Co.). The sequences of the siRNAs targeting different coding regions of the gene were as follows: the sequence of the siRNA-1 sense strand was 5'-GCAGUAACUUGGUAAUUCUTT-3', and the sequence of the antisense strand was 5'-AGAAUUACCAAGUUACUGCTT-3';

the sequence of the siRNA-2 sense strand was 5'-CGGACUAUCACAGGAAAUATT-3',

and the sequence of the antisense strand was

5'-UAUUUCCUGUGAUAGUCCGTT-3'; the sequences of the siRNA-3 sense strand was 5'-GCAGUCUCAUAAGAUUAUATT-3', and the sequence of the antisense strand was 5'-UAUAAUCUUA UGAGACUGCTT-3'. The sequences used for the negative control (siRNA-NC) were 5'-CGUCAGAGUAUACUAAUAUTT-3' (sense) and 5'-AUAUUAGUAUACUCUGACGTT-3' (antisense). The RNAi fragments were synthesized by Shanghai GenePharma Co., Ltd.

\section{Cell culture and transient transfection}

The HCC cell lines Huh7 and HepG2 were cultured in Dulbecco's modified Eagle medium (DMEM) with high glucose (Gibco), and complete culture solution was used for all other cell lines, which was supplemented with $10 \%$ fetal bovine serum (FBS; Gibco), $100 \mathrm{~g} / \mathrm{l}$ penicillin, and $100 \mathrm{~g} / 1$ streptomycin (Invitrogen). All cells were cultured at $37^{\circ} \mathrm{C}$, and the $\mathrm{CO}_{2}$ concentration was $50 \mathrm{ml} / \mathrm{l}$. The cell growth was observed every 2 days, and $2.5 \mathrm{~g} / 1$ trypsin digestion was conducted for subculturing. The cells were transferred to 6-well plates, and serum-free medium was used when the cells reached approximately $70 \%$ confluence. We used Lipofectamine ${ }^{\mathrm{TM}} 3000$ (Invitrogen) for the transient transfection of cells with siRNA-1, siRNA-2 and siRNA-3. A negative control group (siRNANC) and a blank group were included as controls. After 4 to 6 hours of transfection, the cells were switched to DMEM complete medium, and the cells were collected after 72 hours of culture. The TRIzol reagent was used for total RNA extraction and the analysis of the inhibitory effects of the RNAi.

\section{CCK-8 assay for cell growth}

We selected the siRNA sequences (siRNA-1) with the best inhibitory effects to conduct the subsequent experiments. After 24 hours of cell transfection, we adjusted the cell concentration of each group to $2 \times 10^{4 /}$ 
$\mathrm{ml}$, inoculated the cells onto 96-well plates with 100 $\mathrm{ml}$ of medium per well, and placed them in humidified incubators at $37^{\circ} \mathrm{C}$ and $5 \% \mathrm{CO}_{2}$ for cultivation. The cells were grown to $30 \%-50 \%$ confluence and then transfected with the synthetic siRNAs at final concentrations of 50 $\mathrm{nM}$ using the Lipofectamine ${ }^{\mathrm{TM}} 3000$ transfection reagent, according to the manufacturer's instructions. The cells were then sub-cultured at 24-hour intervals for 7 days. The cell viability was measured using CCK-8 according to the manufacturer's instructions. In brief, $10 \mu \mathrm{l}$ of CCK8 solution was added to each well of the plate, and the plate was incubated at $37^{\circ} \mathrm{C}$ for 1 hour. The absorbance was measured at $450 \mathrm{~nm}$ to assess the cell viability. All experiments were independently repeated at least 3 times.

\section{The scratch test to determine the cell migration}

Cells in the logarithmic growth phase were plated into 6 -well plates at $37^{\circ} \mathrm{C}, 5 \% \mathrm{CO}_{2} / 95 \%$ air for 24 hours We used the lance point of a $2-\mu$ l pipette to make a scratch in each well, and we applied serum-free media to gently clear the cells from the scratched area. For each group, 3 parallel samples were evaluated for the ability of the cells to grow into the scratch.

\section{Test of the in vitro cell invasion}

A total of $600 \mu \mathrm{l}$ of DMEM or MEM complete medium was put into the lower chamber of a Transwell plate (including $100 \mathrm{~g} / 1$ penicillin, $100 \mathrm{~g} / 1$ streptomycin and $10 \% \mathrm{FBS}$ ). The upper chamber was filled with 100 $\mu \mathrm{L}$ DMEM, and the plates were allowed to equilibrate overnight in an incubator. The cultured cells were detached from the wells and then resuspended in DMEM. The media was removed from the Transwell plates, and the upper chamber was washed 3 times with DMEM and returned to the lower chamber. The upper chamber was filled with $100 \mu$ of cell suspension, with $1 \times 10^{4}$ cells per well, and the lower chamber was filled with DMEM medium containing $20 \% \mathrm{FBS}$. After 24 hours at $37^{\circ} \mathrm{C}$, the upper chamber was removed and cleaned using cotton balls that had been dipped into PBS solution. Then, 70\% carbinol was used to fix the cells on the membrane for 20 minutes, followed by staining with $0.5 \%$ crystal violet (CV) for 5 minutes and 3 washes with water. Finally, the membrane was placed on a glass slide, with its bottom side facing up. The membrane was then sealed on the slide with a cover after dripping resin onto it. Two double-blind experimenters counted 5 cells at random in their field of vision 100 times, and the average value was considered to represent the numbers of cells that had invaded across the Transwell membrane in the siRNA-1 and siRNA-NC groups. Each group included 3 parallel samples.

\section{Bisulfite DNA sequencing}

Genomic DNA was extracted from the tissue samples using the DNeasy Tissue Kit (Qiagen) according to the manufacturer's instructions. Bisulfite treatment of the genomic DNA was performed using the EpiTect Bisulfite Kit (Qiagen) according to the manufacturer's instructions. For bisulfite DNA sequencing, the $\mathrm{CpG}$ island was amplified using 5'TTAAAGTATTGAGAGTTTAGGAGTAG-3' (forward) and 5'- CATTAACTACTTTCCTTCCAATAAC-3' (reverse), which are primers specific for the FAM $83 D$ gene promoter. The PCR products were purified and subcloned into the pMD18-T vector (TaKaRa). Colonies were selected at random colonies for sequencing.

\section{Statistical analysis}

The SPSS13.0 software program was used for the statistical analyses. The Pearson Chi-square test was used to compare qualitative variables, and quantitative variables were analyzed by the independent $t$-test. The survival probability was estimated by the Kaplan-Meier method, and the log-rank test was used to compare the survival curves between the groups. Stepwise Cox proportional hazard models were used to identify independent predictors associated with the DFS and OS. Differences between the mean values were considered significant when $P<0.05$.

\section{ACKNOWLEDGMENTS}

We gratefully acknowledge support from the National High Technology Research and Development Program of China (2012AA02A205), the Chinese National Key Program on Basic Research (2014CB965002), the National Natural Science Foundation of China (81260328, 81372163, 81472639 and 81272306), the Shanghai Commission for Science and Technology (11JC1408800, 13431902000), Program of Shenzhen Science Technology and Innovation Committee (JCYJ20130329171031740, CXZZ20130515163643 and JCYJ20120831144704366).

\section{CONFLICTS OF INTEREST}

There is no conflict of interest.

\section{REFERENCES}

1. Forner A, Llovet JM and Bruix J. Hepatocellular carcinoma. Lancet. 2012; 379, 1245-1255.

2. Poon RT. Prevention of recurrence after resection of hepatocellular carcinoma: a daunting challenge. Hepatology. 2011; 54:757-759. 
3. Tralhão JG, Dagher I, Lino T, Roudié J, and Franco D. Treatment of tumour recurrence after resection of hepatocellular carcinoma. Analysis of 97 consecutive patients. Eur J Surg Oncol. 2007; 33:746-751.

4. Shimada K, Sano T, Sakamoto Y, and Kosuge T. A longterm follow-up and management study of hepatocellular carcinoma patients surviving for 10 years or longer after curative hepatectomy. Cancer. 2005; 104:1939-1947.

5. Huang J, Zheng DL, Qin FS, Cheng N, Chen H, Wan BB, Wang YP, Xiao HS, and Han ZG. Genetic and epigenetic silencing of SCARA5 may contribute to human hepatocellular carcinoma by activating FAK signaling. J Clin Invest. 2010; 120:223-241.

6. Liao W, Liu W, Yuan Q, Liu X, Ou Y, He S, Yuan S, Qin L, Chen Q, Nong K, Mei M, and Huang J. Silencing of DLGAP5 by siRNA significantly inhibits the proliferation and invasion of hepatocellular carcinoma cells. PLoS One. 2013; 8:e80789.

7. Deloukas P, Matthews LH, Ashurst J, Burton J, Gilbert JG, Jones M, Stavrides G, Almeida JP, Babbage AK, Bagguley CL, Bailey J, Barlow KF, Bates KN, et al. The DNA sequence and comparative analysis of human chromosome 20. Nature. 2001; 414:865-871.

8. Santamaria A, Nagel S, Sillje $\mathrm{HH}$, and Nigg EA. The spindle protein CHICA mediates localization of the chromokinesin Kid to the mitotic spindle. Curr Biol. 2008; 18:723-729.

9. Varisli L. Meta-analysis of the expression of the mitosisrelated gene Fam83D. Oncol Lett. 2012; 4:1335-1340.

10. Sauer G, Körner R, Hanisch A, Ries A, Nigg EA, and Silljé $\mathrm{HH}$. Proteome analysis of the human mitotic spindle. Mol Cell Proteomics. 2005; 4:35-43.

11. He J, Wu J, Xu N, Xie W, Li M, Li J, Jiang Y, Yang BB, and Zhang Y. MiR-210 disturbs mitotic progression through regulating a group of mitosis-related genes. Nucleic Acids Res. 2013; 41:498-508.

12. Wang Z, Liu Y, Zhang P, Zhang W, Wang W, Curr K, Wei $\mathrm{G}$, and Mao JH. FAM83D promotes cell proliferation and motility by downregulating tumor suppressor gene FBXW7. Oncotarget. 2013; 4:2476-2486.

13. Cipriano R, Miskimen KL, Bryson BL, Foy CR, Bartel CA, and Jackson MW. Conserved oncogenic behavior of the FAM83 family regulates MAPK signaling in human cancer. Mol Cancer Res. 2014; 12:1156-1165.

14. Nathan H, Schulick RD, Choti MA, and Pawlik TM. Predictors of survival after resection of early hepatocellular carcinoma. Ann Surg. 2009; 249:799-805.

15. Ercolani G, Grazi GL, Ravaioli M, Del Gaudio M, Gardini A, Cescon M, Varotti G, Cetta F, and Cavallari A. Liver resection for hepatocellular carcinoma on cirrhosis: univariate and multivariate analysis of risk factors for intrahepatic recurrence. Ann Surg. 2003; 237:536-543.

16. Wang T, Hu HS, Feng YX, Shi J, Li N, Guo WX, Xue J, Xie D, Liu SR, Wu MC, and Cheng SQ. Characterisation of a novel cell line (CSQT-2) with high metastatic activity derived from portal vein tumour thrombus of hepatocellular carcinoma. Br J Cancer. 2010; 102:1618-1626.

17. Kinoshita A, Onoda H, Imai N, Iwaku A, Oishi M, Fushiya N, Koike K, Nishino H, and Tajiri H. Comparison of the prognostic value of inflammation-based prognostic scores in patients with hepatocellular carcinoma. Br J Cancer. 2012; 107:988-993.

18. Pinato DJ, Stebbing J, Ishizuka M, Khan SA, Wasan HS, North BV, Kubota K, and Sharma R. A novel and validated prognostic index in hepatocellular carcinoma: the inflammation based index (IBI). J Hepatol. 2012; 57:10131020.

19. Oh BS, Jang JW, Kwon JH, You CR, Chung KW, Kay CS, Jung HS, and Lee S. Prognostic value of C-reactive protein and neutrophil-to-lymphocyte ratio in patients with hepatocellular carcinoma. BMC Cancer. 2013; 13:78.

20. Liao W, Zhang J, Zhu Q, Qin L, Yao W, Lei B, Shi W, Yuan S, Tahir SA, Jin J, and He S. Preoperative Neutrophilto-Lymphocyte Ratio as a New Prognostic Marker in Hepatocellular Carcinoma after Curative Resection. Transl Oncol. 2014; 7:248-255.

21. Peng SY, Chen WJ, Lai PL, Jeng YM, Sheu JC, and Hsu HC. High alphafetoprotein level correlates with high stage, early recurrence and poor prognosis of hepatocellular carcinoma: significance of hepatitis virus infection, age, p53 and beta-catenin mutations. Int J Cancer. 2004; 112:44-50.

22. Cheng CH, Lee CF, Wu TH, Chan KM, Chou HS, Wu TJ, $\mathrm{Yu}$ MC, Chen TC, Lee WC, and Chen MF. Evaluation of the new AJCC staging system for resectable hepatocellular carcinoma. World J Surg Oncol. 2011; 9:114.

23. Kow AW, Kwon CH, Song S, Shin M, Kim JM, and Joh JW. Risk factors of peritoneal recurrence and outcome of resected peritoneal recurrence after liver resection in hepatocellular carcinoma: review of 1222 cases of hepatectomy in a tertiary institution. Ann Surg Oncol. 2012; 19:2246-2255.

24. Cha C, Fong Y, Jarnagin WR, Blumgart LH, and DeMatteo RP. Predictors and patterns of recurrence after resection of hepatocellular carcinoma. J Am Coll Surg. 2003; 197:753758.

25. Pinter M, Sieghart W, Hucke F, Graziadei I, Vogel W, Maieron A, Königsberg R, Weissmann A, Kornek G, Matejka J, Stauber R, Buder R, Grünberger B, et al. Prognostic factors in patients with advanced hepatocellular carcinoma treated with sorafenib. Aliment Pharmacol Ther. 2011; 34:949-959.

26. Huitzil-Melendez FD, Capanu M, O’Reilly EM, Duffy A, Gansukh B, Saltz LL, and Abou-Alfa GK. Advanced hepatocellular carcinoma: which staging systems best predict prognosis? J Clin Oncol. 2010; 28:2889-2895.

27. Chang ML, Lin SM, and Yeh CT. HURP ExpressionAssisted Risk Scores Identify Prognosis Distinguishable Subgroups in Early Stage Liver Cancer. PLoS One. 2011; 
6:e26323.

28. Llovet JM, Schwartz M, and Mazzaferro V. Resection and liver transplantation for hepatocellular carcinoma. Semin Liver Dis. 2005; 25:181-200.

29. Hoshida Y, Villanueva A, Kobayashi M, Peix J, Chiang DY, Camargo A, Gupta S, Moore J, Wrobel MJ, Lerner J, Reich M, Chan JA, Glickman JN, et al. Gene expression in fixed tissues and outcome in hepatocellular carcinoma. N Engl J Med. 2008; 359:1995-2004.

30. Zhou L, Rui JA, Wang SB, Chen SG, and Qu Q. Prognostic factors of solitary large hepatocellular carcinoma: the importance of differentiation grade. Eur J Surg Oncol. 2011; 37:521-525.

31. Tang ZY, Ye SL, Liu YK, Qin LX, Sun HC, Ye QH, Wang L, Zhou J, Qiu SJ, Li Y, Ji XN, Liu H, Xia JL, et al. A decade's studies on metastasis of hepatocellular carcinoma. J Cancer Res Clin Oncol. 2004; 130:187-196.

32. Sun BS, Dong QZ, Ye QH, Sun HJ, Jia HL, Zhu XQ, Liu DY, Chen J, Xue Q, Zhou HJ, Ren N, and Qin LX. Lentiviral-mediated miRNA against osteopontin suppresses tumor growth and metastasis of human hepatocellular carcinoma. Hepatology. 2008; 48:1834-1842.

33. Brower V. RNA interference advances to early-stage clinical trials. J Natl Cancer Inst. 2010; 102:1459-1461. 